\title{
The effects of four primers and two cement types on the bonding strength of zirconia
}

\author{
Yang Cao ${ }^{1}$, Jia-Feng Zhang ${ }^{2}$, Xin Ou ${ }^{2}$, Bao Zhang ${ }^{2}$, Lei Chen ${ }^{3}$, Xue-Hua Deng ${ }^{4}$ \\ ${ }^{1}$ Medical Equipment Department, Xiangya Hospital of Central South University, Changsha, China; ${ }^{2}$ National Engineering Laboratory for High \\ Efficiency Recovery of Refractory Nonferrous Metals, School of Metallurgy and Environment, Central South University, Changsha, China; ${ }^{3}$ Center \\ of Stomatology, Xiangya Hospital of Central South University, Changsha, China; ${ }^{4}$ Department of Prosthodontics, Changsha Stomatological \\ Hospital, Changsha, China \\ Contributions: (I) Conception and design: L Chen, XH Deng; (II) Administrative support: B Zhang, L Chen; (III) Provision of study materials or \\ patients: XH Deng, L Chen; (IV) Collection and assembly of data: XH Deng, Y Cao; (V) Data analysis and interpretation: XH Deng, Y Cao; (VI) \\ Manuscript writing: All authors; (VII) Final approval of manuscript: All authors. \\ Correspondence to: Lei Chen. Center of Stomatology, Xiangya Hospital of Central South University, Changsha 410008, China. Email: Chenleidt@163.com; \\ Xue-Hua Deng. Department of Prosthodontics, Changsha Stomatological Hospital, Changsha, China. Email: 530487181@qq.com.
}

Background: To evaluate the effects of four ceramic primers and two cement types on the bonding strength and durability between zirconia and resin cement.

Methods: A total of 115 polished and air-abraded zirconia blocks were randomly divided into five groups (with 23 in each group) to test the performance of various primers. Meanwhile, all primer samples were divided into two subgroups randomly to measure the difference between the two cement types. Group No treat - Clearfil SA Cement (NT-C); group No treat - RelyX Unicem Cement (NT-U); group Z-Prime Plus - Clearfil SA Cement (ZPP-C); group Z-Prime Plus - RelyX Unicem Cement (ZPP-U); group Rely X Ceramic Primer - Clearfil SA Cement (RCP-C); group Rely X Ceramic Primer - RelyX Unicem Cement (RCP-U); group Clearfil Ceramic Primer - Clearfil SA Cement (CCP-C); group Clearfil Ceramic Primer RelyX Unicem Cement (CCP-U); group Monobond-S - Clearfil SA Cement (MS-C); group Monobond-S RelyX Unicem Cement (MS-U). According to the type of cement, the specimens were randomly selected for electron microscope scanning and energy spectrum analysis, and the tightness of zirconium porcelain resin adhesive interface was observed. The bonding strength of different adhesives and aging experiments were tested by shear test mode, and the shear strength of each experimental group was analyzed by one variable three factor analysis of variance.

Results: All primers in the treated groups maintained a pristine structure without micro-crack, while the non-primer treatment sample exhibited obvious micro-cracks. Furthermore, among the four primers, the sample treated with Clearfil Ceramic Primer (CCP) obtained the highest bonding strength, with a statistically significant difference $(\mathrm{P}<0.05)$. However, cohesive failure mainly occurred in the CCP group before thermal cycles, and mixed failure occurred after thermal cycles.

Conclusions: CCP is the superior primer, and can improve the bonding strength between zirconia and resin cement. Because the thermal cycles have a significantly adverse effect on the shear bond strength, CCP can be helpful in improving the durability of the zirconia bonding strength. Furthermore, the two cement types exhibited a similar bonding performance for zirconia.

Keywords: Zirconia; primer; cement; thermocycling; bonding strength

Submitted Aug 05, 2021. Accepted for publication Jan 05, 2022.

doi: 10.21037/atm-21-4909

View this article at: https://dx.doi.org/10.21037/atm-21-4909 


\section{Introduction}

Due to the advantages of high strength, good tenacity, excellent fatigue resistance, low thermal conductivity, and the accessible design and manufacturing technology of computer-aided (CAD/CAM) precision, zirconium dioxide ceramics are the perfect substitute for traditional metal and metal-ceramic restoration. Clinically, zirconium dioxide ceramics have been widely used as the basic material in joint replacements and tooth, including as a zirconia all-porcelain crown, fixed bridge, an all-porcelain post and core, an implant and implant abutment, etc. (1).

Excellent adhesion performance is the crucial factor for the ceramic restoration to operate in the mouth for an extended period of time without falling off or being damaged. The consensus for the bonding technology of glass ceramics is treatment with hydrofluoric (HF) acid corrosion and surface silicon alkylation. In contrast to glass ceramics, glass structure and silicate compositions are absent in the zirconia ceramics, whose porcelain surface is biologically inert and can thus avoid traditionally problematic acid corrosion and silicon alkylation which make bonding to the preparation abutment challenging (2). However, good bonding between the abutment and the zirconic porcelain restoration is the prerequisite to ensure the restoration retention force, marginal adaptation, and the prevention of secondary caries (3). At present, the research on the oxide zirconium adhesion has mainly focused on micromechanical interlocking fixation (surface roughening) and chemical bonding (surface activation) (4).

Currently, the commonly used methods of locking and fixing micro-machinery include surface sandblasting, surface acid etching, and laser pretreatment. It has been found that the acid corrosion of selective permeability can make the zirconic porcelain surface rough and porous and improve the bonding effect. However, the adhesive durability has not been confirmed (5). Studies have demonstrated that using alumina to sandblast the surface of the zirconic porcelain can increase the surface roughness and wettability $(6,7)$. Rocca et al. reported that making use of surface treatment $\mathrm{CO}_{2}$ and Neodymium: Yttrium orthoaluminate (Nd:YAP) laser is a feasible way to improve the mechanical retention force between the zirconic porcelain and the adhesives, although its effect was only barely comparable to that of the sandblasting group (8).

Due to the compact polycrystalline structures on the surface of zirconium oxide, a certain strength is needed to provide sufficient mechanical position force for these coarsening methods. Meanwhile, excessive surface roughening may lead to micro fracture on the zirconium ceramic surface, and subsequent stress-induced crack extension can increase the risk of repair failure (9). Meanwhile, the commonly used methods for adhesion fixation include primer treatment, surface silanisation, silicon coating, and surface glazing technology $(10,11)$. Bottino et al. found that the surface of zirconium oxide merely treated by the silanisation could barely achieve a satisfactory adhesion effect (9). Liu et al. confirmed that surface glazing was able to improve the bonding strength between the zirconia and the resins, but could barely withstand the hydrolysis of cold and hot circulation (12). Although silicon coating can improve the adhesion of zirconia, it is inconvenient for the clinical application as it is time-consuming, while it is difficult to precisely control the concentration of silicon solution during the sintering process (13).

Numerous studies have confirmed that silicon coating is unable to obtain ideal bonding strength and durability of the zirconic ceramics by the single method of mechanical or chemical retention (13). Therefore, jointly using two methods is recommended to significantly improve the adhesion of the zirconic ceramics, which can include sandblasting and silicone coating, laser ablation, and silanization (14). Meanwhile, some researchers have proposed that the adhesives with 10-Methacryloyloxydecyl dihydrogen phosphate (MDP) can improve the adhesion durability after the surface roughening of the zirconic porcelain $(15,16)$. Despite this research, few studies have investigated the joint application of surface roughing, primer coating, and MDP adhesives.

In recent years, a variety of coating primers have been developed for application of zirconium oxide, and these most rely on functional adhesive monomers, such as MDP, bisphenol A-glycidyl methacrylate (Bis-GMA), and thiophosphoric methacrylate (MEPS), and others to form an active chemical reaction interface on the porcelain surface, increasing the adhesion between the zirconic porcelain and resins (17). Most of the relevant research has mainly focused on the coating primers containing MDP. Inokoshi et al. believed that the combined use of coating primers and resins containing MDP could improve the adhesion of zirconic ceramics, forming a reliable and durable adhesion between the resins and zirconium (18). However, Ozcan et al. believed that although the use of the coating primers containing MDP can increase the adhesion, it cannot easily tolerate the cold and hot circulation, resulting in the 
decrease of hydrolysis stability at the bonding interface (19). Meanwhile, $\mathrm{Wu}$ et al. reported that coating primers could improve the short-term bonding strength of zirconia, although its adhesion effect was still weaker than that of the silicon coating method (20). Furthermore, the comparative study between coating primers containing MDP and other functional monomers is extremely rare.

As indicated above, the optimal bonding combination schemes for mechanical and chemical fixation is controversial, and there is a lack of in-depth study concerning the treatment effects of different types of coating primers and hydrolysis stability. Therefore, improving the adhesion of the zirconic ceramics is still an urgent challenge. In this work, the effects of four novel coating primers-the Z-Prime Plus (ZPP), the Rely X Ceramic Primer (RCP), the Clearfil Ceramic Primer (CCP), the Monobond-S (MS) and commonly used resin adhesives on the bonding strength of zirconic ceramics were evaluated, with the adhesion durability being measured by artificial aging in vitro. At the same time, the chemical reactions between their monomer components were studied. The appropriate plan, with relatively simple operation for improved bonding strength of zirconia, can provide a reference for the clinical selection of a zirconic restoration bonding system.

\section{Methods}

A total of $115 \mathrm{ZrO}_{2}$ ceramic blocks, $10 \mathrm{~mm} \times 8 \mathrm{~mm} \times 2 \mathrm{~mm}$ in size, of high purity (L2150603106, Shenzhen Upcera Co., Ltd, China) were densely sintered at $1,450{ }^{\circ} \mathrm{C}$ for 12 hours according to the manufacturer's instructions.

The ceramic specimens were polished consecutively with 400, 800, and 1,200 grit silicon carbide papers (400\#, 800\#, $1200 \#, 3 \mathrm{M} 401 \mathrm{Q}$, USA) under water cooling at $500 \mathrm{rpm}$ using a polishing machine (MP-2B, Laizhou Weiyi Experiment Machine Manufacturing Co., Ltd, China) to achieve a standardized surface roughness, and then cleaned ultrasonically for $5 \mathrm{~min}$.

The bonding surfaces of the ceramic samples were abraded with air-borne particles (C00739, Renfert. Co, Germany), using $50 \mu \mathrm{m} \mathrm{Al}_{2} \mathrm{O}_{3}$ for $10 \mathrm{~s}$ at a compressed air pressure of $0.5 \mathrm{MPa}$ with a stand-off distance of $10 \mathrm{~mm}$, perpendicular to the surface to remove the investment, and then cleaned ultrasonically for $5 \mathrm{~min}$.

\section{Preparation of samples}

To standardize the bonding area between zirconia and cement, a customized mold that tightly matched the zirconia blocks and the cement blocks was made with a numerical lathe. This jig on one side was a rectangular chamber $30 \mathrm{~mm} \times 30 \mathrm{~mm} \times 10 \mathrm{~mm}$ on one side, matching the zirconia blocks, and had a rectangular section of $4 \mathrm{~mm}$ $\times 4 \mathrm{~mm} \times 2 \mathrm{~mm}$ on the other side, matching the cement blocks (FS-1 type light cured composite resin).

After the zirconia block was positioned, cement was prepared according to the manufacturers' instructions, and the mold was filled to create rectangular cement blocks that were bonded directly to the rectangular zirconia blocks (Figure 1). The resin cement was then light-polymerized (D-2000, Apoza Enterprise., Taiwan) from the top surface for 40 seconds.

In all, 115 samples were randomly divided into five groups $(n=23)$, as shown in Table 1 . One sample was randomly selected in each group for scanning electron microscopy and energy spectrum analysis. The rest 110 samples were further divided into 10 subgroups $(n=11)$, according to the type of adhesive (Table 1). All specimens were placed at room temperature for $30 \mathrm{~min}$, and then one sample was randomly selected in each group for scanning electron microscope and energy spectrum analysis. The materials evaluated in this study are summarized in Table 2.

The specimens were then fixed to a specially fabricated jig and mounted to a universal testing machine (MTS-585, MTS, USA) and a load was applied at a crosshead speed of $0.5 \mathrm{~mm} / \mathrm{min}$ until failure. The maximum force at debonding was recorded, and the shear bond strength was calculated.

Thermal cycling was conducted using a programmable refrigerated heating circulator with a water-cooling machine (HHS-S, Unistat $510 \mathrm{w}$; Huber) between 5 and $55{ }^{\circ} \mathrm{C}$ for 2,500 cycles, with a dwell time of $15 \mathrm{~min}$ and $30 \mathrm{~s}$. The profile was believed to better simulate the real temperature variation which the bonding systems undergo in clinic.

\section{Characterizations}

One specimen from each group was randomly selected and coated with gold before scanning electron microscope (SEM) (JSM-6360LV, JEOL, Kyoto, Japan) examination. The acceleration voltage of SEM was set to $20 \mathrm{kV}$, and the images were taken at magnifications of 1,000 times.

Specimens are collected using a slow cutting machine (M618, Jiangsu Nantong machine tool factory, China), applied perpendicular to the bonding interface between the resin and cement. Then, 400\# and 800\# sand paper was used for polishing, and after polishing, the specimens 


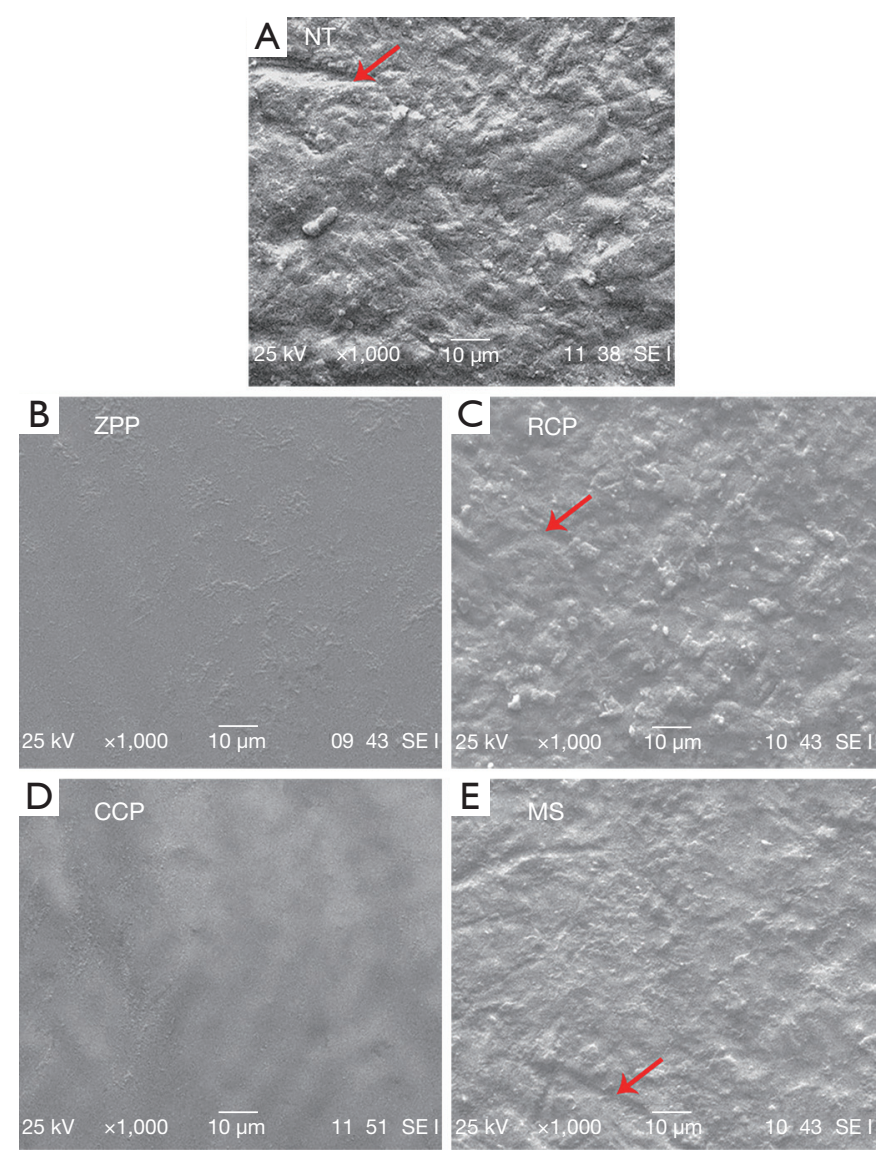

Figure 1 Observation of surface microstructure for the porcelain plate after primer treatment. (A) NT group, (B) ZPP group, (C) RCP group, (D) CCP group, and (E) MS group. The NT group had an irregular rough surface after sandblasting (the arrows indicate the deep cracks). The ZPP and CCP groups had a smooth surface, but the rough surface can also be faintly seen. The RCP and MS groups showed a decrease in roughness (the arrow indicates the shallow crack).

Table 1 The grouping of the primer and cement types

\begin{tabular}{lll}
\hline Groups & Primer & Cement \\
\hline NT-C & No treat & Clearfil SA Cement \\
NT-U & No treat & RelyX Unicem Cement \\
ZPP-C & Z-Prime Plus & Clearfil SA Cement \\
ZPP-U & Z-Prime Plus & RelyX Unicem Cement \\
RCP-C & Rely X Ceramic Primer & Clearfil SA Cement \\
RCP-U & Rely X Ceramic Primer & RelyX Unicem Cement \\
CCP-C & Clearfil Ceramic Primer & Clearfil SA Cement \\
CCP-U & Clearfil Ceramic Primer & RelyX Unicem Cement \\
MS-C & Monobond-S & Clearfil SA Cement \\
MS-U & Monobond-S & RelyX Unicem Cement \\
\hline
\end{tabular}

NT-C, group No treat - Clearfil SA Cement; NT-U, group No treat - RelyX Unicem Cement; ZPP-C, group Z-Prime Plus - Clearfil SA Cement; ZPP-U, group Z-Prime Plus - RelyX Unicem Cement; RCP-C, group Rely X Ceramic Primer - Clearfil SA Cement; RCP-U, group Rely X Ceramic Primer - RelyX Unicem Cement; CCP-C, group Clearfil Ceramic Primer - Clearfil SA Cement; CCP-U, group Clearfil Ceramic Primer - RelyX Unicem Cement; MS-C, group Monobond-S - Clearfil SA Cement; MS-U, group Monobond-S - RelyX Unicem Cement. 
Table 2 Materials used in the experiment

\begin{tabular}{|c|c|c|c|}
\hline Study materials & Composition & Lot & Manufacturer \\
\hline $\begin{array}{l}\text { RelyX } \\
\text { Ceramic Primer }\end{array}$ & $\begin{array}{l}\text { A silane, 3-methacryloyloxypropyl trimethoxysilane (3-MPS); } \\
\text { ethanol, water }\end{array}$ & N-387580 & 3M ESPE, USA \\
\hline $\begin{array}{l}\text { Clearfil Ceramic } \\
\text { Primer }\end{array}$ & 10-MDP, 3-MPS, methylacrylic monomer (HEMA), ethanol & $00282 \mathrm{C}$ & Kuraray Medical, Tokyo, Japan \\
\hline Monobond-S & $\begin{array}{l}\text { Alcohol, silane, methacrylate, phosphoric-acid methacrylate, } \\
\text { sulphide methacrylate }\end{array}$ & $\mathrm{T}-10752$ & Ivoclar Vivadent, Germany \\
\hline ClearfilSA Cement & $\begin{array}{l}\text { Paste A: Bis-GMA, TEGDMA, MDP, DMA, silanated barium glass } \\
\text { filler, silanated colloidal silica Paste B: Bis-GMA, DMA, silanated } \\
\text { barium glass filler, silanated colloidal silica, surface treated sodium } \\
\text { fluoride }\end{array}$ & 071142 & Kuraray Medical, Tokyo, Japan \\
\hline RelyX Unicem & $\begin{array}{l}\text { Powder: glass particles, initiators, silica, substituted pyrimidine, } \\
\text { calcium hydroxide, peroxide composite and pigment Liquid: } \\
\text { methacrylate phosphoric acid ester, DMA, acetate, stabilizer and } \\
\text { initiator }\end{array}$ & 564262 & 3M ESPE. USA \\
\hline $\begin{array}{l}\text { FS-1 Composite } \\
\text { Resin }\end{array}$ & $\begin{array}{l}\text { BOWEN resin, diluent, barium glass fillers treated by silylation; } \\
\text { Bis-GMA, DMA, inorganic fillers, ytterbium trifluoride, initiators, } \\
\text { stabilizers and pigments }\end{array}$ & 140409 & $\begin{array}{l}\text { Shanghai Eryi Zhangjiang } \\
\text { Biomaterial Co., Ltd., China }\end{array}$ \\
\hline
\end{tabular}

were cleaned in distilled water by ultrasonic cleaning for 5 minutes, followed by drying and sputtering with gold. Finally, the specimens were evaluated with a SEM (JSM6360LV, JEOL ltd., Kyoto, Japan).

The specimens were then fixed to a specially fabricated jig and mounted to a universal testing machine (MTS585, MTS, USA), and a load was applied at a crosshead speed of $0.5 \mathrm{~mm} / \mathrm{min}$ until failure. The maximum force at debonding was recorded, and the shear bond strength (SBS) was calculated.

After SBS testing, the fractured interface was examined using stereomicroscopy (magnification $\times 30$; KH7700, Hirox, Japan). The specimens were classified according to fracture patterns: type I: adhesive failure, type II: mixed failure (combination of cohesive and adhesive failure), and type III: cohesive failure.

\section{Statistical analysis}

Software SPSS 19.0 was used to analyze the surface roughness of the specimens by univariate analysis of variance. If there were differences, Tukey's multiple comparison analysis was performed. Multiple comparison in the experimental group was compared with the StudentNewman-Keuls test, with the test level being alpha $=0.05$. A $\mathrm{P}$ value $<0.05$ indicated a statistically significant difference.

\section{Results}

\section{Adhesive shear strength}

Table 3 display the mean bond strength and standard deviations associated with the thermal cycling processes and surface conditioning methods. The three factors of this experiment were the coating primers, the adhesives, and the cold-hot circulation. As shown in Table 4, the values of $\mathrm{P}$ between the cold-hot circulation and the coating primers, between the cold-hot circulation and the adhesives, between the coating primers and the adhesives, and among the coating primers, adhesives, and cold-hot circulation were $0.604,0.055,0.465$, and 0.150 , respectively. This experiment found no significant interactions among the three factors. When the main effects of the coating primers were investigated, the $\mathrm{P}$ value was 0.000 . The shear strength differences with different coating primers were statistically significant. When the main effects of the cold- 
Table 3 Average shear strength of each experimental group $(\mathrm{MPa}, \mathrm{n}=5, \mathrm{P}<0.05)$

\begin{tabular}{|c|c|c|c|c|}
\hline Groups & \multicolumn{2}{|c|}{ After 24 hours of water storage } & \multicolumn{2}{|c|}{ After 2,500 thermal cyclings } \\
\hline No treat & $8.01 \pm 0.98^{\mathrm{Da}}$ & $8.23 \pm 1.05^{\mathrm{Aa}}$ & $5.79 \pm 1.46^{\mathrm{Cb}}$ & $5.55 \pm 1.01^{\mathrm{cb}}$ \\
\hline Z-Prime Plus & $12.15 \pm 1.70^{\mathrm{BCa}}$ & $12.14 \pm 2.14^{\mathrm{Ba}}$ & $8.05 \pm 1.89^{\mathrm{Bb}}$ & $8.23 \pm 1.41^{\mathrm{Bb}}$ \\
\hline Rely X Ceramic Primer & $11.84 \pm 1.76^{\mathrm{Ca}}$ & $10.72 \pm 1.92^{\mathrm{Aa}}$ & $8.09 \pm 1.52^{\mathrm{Bb}}$ & $8.59 \pm 1.89^{\mathrm{Bb}}$ \\
\hline Monobond-S & $12.49 \pm 1.46^{\mathrm{Ba}}$ & $10.73 \pm 1.03^{\mathrm{Ab}}$ & $9.27 \pm 1.52^{\mathrm{Ac}}$ & $8.02 \pm 1.29^{\mathrm{Bd}}$ \\
\hline
\end{tabular}

Same uppercase superscript letters within the same column show no statistically significant differences among primers [Tukey's honestly significant difference (HSD), P>0.05]. Same lowercase superscript letters within the same row show no statistically significant differences among aging treatments and thermal cyclings (Tukey's HSD, $P>0.05$ ).

Table 4 The results of three factor variance analysis (with the dependent variable being SBS)

\begin{tabular}{lcccc}
\hline Source & Sum of squares & df & Mean square & $F$ \\
\hline Corrected model & $603.068 \mathrm{a}$ & 19 & 31.740 & 13.326 \\
Intercept & $9,811.260$ & 1 & $9,811.260$ & $4,119.314$ \\
Primers & 323.666 & 4 & 80.916 & 33.973 \\
Cements & 6.433 & 1 & 6.433 & 2.701 \\
Thermalcycling & 232.227 & 1 & 232.227 & 9.000 \\
Primers * cements & 8.620 & 4.502 & 0.000 \\
Primers * thermal cycling & 6.531 & 4 & 2.155 & 0.905 \\
Cements * thermal cycling & 9.023 & 1.633 & 0.685 \\
Primers * cements * thermal cycling & 16.568 & 4 & 9.023 & 3.788 \\
Error & 190.542 & 80 & 4.142 & 1.739 \\
Total & $10,604.870$ & 100 & 2.382 & 0.604 \\
Total correction & 793.610 & 99 & & 0.150 \\
\hline
\end{tabular}

hot circulation were investigated, the $\mathrm{P}$ was also 0.000 . The shear strength difference before and after the cold-hot circulation showed statistical significance. When examining the effect of the adhesives, the $\mathrm{P}$ was 0.104 , indicating that there was no significant difference of shear between the two adhesives.

Tukey's multiple comparison analysis showed that the shear strength of the Z-Prime Plus, Rely X Ceramic Primer, Clearfil Ceramic Primer, and Monobond-S groups was significantly higher than that of the NT group (without using the coating primers). Among the four types of coating primers, the shear strength of the CCP group was significantly better than that of the other three groups, which shared a similar shear strength.
Before the cold-hot circulation, all the groups, except for the RCP-U and the MS-U groups, were significantly different from the NT group, while the CCP-C and the $\mathrm{CCP}-\mathrm{U}$ groups showed the highest shear strength. After cold-hot circulation, the shear strength of the CCP-C and $\mathrm{CCP}-\mathrm{U}$ groups was significantly higher than that of the other experimental groups, while the ZPP, RCP, and MS groups showed no difference from the NT groups.

\section{Bond failure type}

Under a 3D video microscope with $30 x$, the surface of the ceramics and resin flakes after bonding damage was examined. Based on the classification and statistics and 
Table 5 Statistics of each shear failure type in the experimental groups ( $\mathrm{n}=5)$

\begin{tabular}{|c|c|c|c|c|c|c|}
\hline Groups & \multicolumn{3}{|c|}{ After $24 \mathrm{~h}$ of water storage } & \multicolumn{3}{|c|}{ After 2,500 thermal cyclings } \\
\hline NT-C & 3 & 2 & 0 & 4 & 1 & 0 \\
\hline NT-U & 2 & 3 & 0 & 5 & 0 & 0 \\
\hline ZPP-C & 2 & 3 & 0 & 3 & 2 & 0 \\
\hline $\mathrm{RCP}-\mathrm{C}$ & 2 & 3 & 0 & 4 & 1 & 0 \\
\hline RCP-U & 3 & 2 & 0 & 4 & 1 & 0 \\
\hline CCP-C & 1 & 2 & 2 & 1 & 4 & 0 \\
\hline CCP-U & 1 & 3 & 1 & 2 & 3 & 0 \\
\hline
\end{tabular}

NT-C, group No treat - Clearfil SA Cement; NT-U, group No treat - RelyX Unicem Cement; ZPP-C, group Z-Prime Plus - Clearfil SA Cement; ZPP-U, group Z-Prime Plus - RelyX Unicem Cement; RCP-C, group Rely X Ceramic Primer - Clearfil SA Cement; RCP-U, group Rely X Ceramic Primer - RelyX Unicem Cement; CCP-C, group Clearfil Ceramic Primer - Clearfil SA Cement; CCP-U, group Clearfil Ceramic Primer - RelyX Unicem Cement; MS-C, group Monobond-S - Clearfil SA Cement; MS-U, group Monobond-S - RelyX Unicem Cement.

according to the methods described above, in the fracture experiment, in the control group, ZPP group and RCP group, type I damage and type II damage accounted for half of the total samples respectively before the cold-hot circulation, and type I damage was the main one after the cold-hot circulation, meanwhile the type II damage was the main in CCP group and MS group before the cold-hot circulation, and type I damage increased in MS group after the cold-hot circulation. The specific results are detailed below and listed in Table 5 .

Contrast group: before the cold-hot circulation, type I damage and type II damage accounted for half of the total samples respectively. Meanwhile, after cold-hot circulation, type I damage was the main one. ZPP and RCP groups: before the cold-hot circulation, type I damage and type II damage accounted for half of the total samples respectively. After the cold-hot circulation, type I was still the main one, but the damage proportion of type I was lower than that of the contrast group.

CCP group: before the cold-hot circulation, it is mainly type II damage, while type III showed damage. The damage proportion of type III was higher than that of the type I. However, type II damage was still accounts for a high proportion after the cold-hot circulation

MS group: before the cold-hot circulation, type II damage was dominant, and type III damage also appeared. However, type I damage and type II damage accounted for half of the total samples respectively after the cold-hot circulation.

\section{Observation on surface morphology of zirconium porcelain}

The surface microstructures of the metal-spraying ceramic chips after primer coating were magnified up to 1,000 times under electron microscopy, and the observations from this are shown in Figure 1. The surface of the NT group without coating primers was rough and uneven, with some visible cracks being observed presumably caused by the sandblasting of $\mathrm{Al}_{2} \mathrm{O}_{3}$ particles on the porcelain surface. Even though there was some uneven distribution, the porcelain surface treated by the RCP and MS was more regular and less rough than that of the NT group, and the cracks were more superficial. This indicates that the coating primers were fully wetting the surface of the porcelain and penetrating into the concave and convex structures of the porcelain surface with close integration. Meanwhile, the porcelain surface treated by the ZPP and CCP were covered by a thin layer film, and was smoother than that of the other three groups. The irregular surface of the ZPP group could be vaguely seen, and the bubbles of the CCP 
Table 6 The percentage of each element on the surface after treatment (wt\%)

\begin{tabular}{|c|c|c|c|c|c|c|}
\hline Groups & C, wt\% & $\mathrm{N}, \mathrm{wt} \%$ & Si, wt\% & $\mathrm{P}, \mathrm{wt} \%$ & Zr, wt\% & $\mathrm{Au}, \mathrm{wt} \%$ \\
\hline ZPP & 39.11 & 10.00 & 00.74 & 01.07 & 27.16 & 21.94 \\
\hline $\mathrm{RCP}$ & 08.03 & 05.86 & 09.29 & 00.00 & 09.35 & 67.46 \\
\hline CCP & 12.63 & 00.00 & 01.50 & 01.98 & 51.20 & 32.70 \\
\hline
\end{tabular}

NT, no treat; ZPP, the Z-Prime Plus; RCP, the Rely X Ceramic Primer; CCP, the Clearfil Ceramic Primer; MS, the Monobond-S.

group were occasionally visible. In the previous surface treatments, the ZPP and CCP groups were found to be smoother, especially in the CCP group, which is consistent with the microstructures of the porcelain surface.

\section{Surface energy spectrum analysis}

Table 6 displays the mass percentage of the basic elements on the surface of the tiles of each group after primer coating. Figure 2 shows the energy spectrum peak graphs and data on the surface of the tiles for each group. As listed in Figure 2 and Table 6, elements of carbon (C), silicon ( $\mathrm{Si})$, and gold $(\mathrm{Au})$, but not zirconia $(\mathrm{Zr})$, were visible in the NT, ZPP, RCP, CCP, and MS groups, The Au element derives from the metal powder sprayed on the surface of the porcelain. All the tiles are polished by the Silicone water grinding paper. There were still some residuals after polishing with ultrasonic cleaning, which can account for the main source of $\mathrm{C}$ and $\mathrm{Si}$ elements on the porcelain surface. Compared with the NT group, nitrogen $(\mathrm{N})$ and phosphorus $(\mathrm{P})$ elements were observed on the surface of the ZPP and the MS group. There were no $\mathrm{P}$ elements in the RCP group, but the mass percentage of $\mathrm{Si}$ is as high as $9.29 \mathrm{Wt} \%$ in RCP group, while the mass percentage of the $\mathrm{P}$ elements of the CCP group (1.98 Wt\%) was higher than that of the ZPP group (1.07 Wt\%).

\section{Observation of bonding interface}

Figure 3 shows the bonding interface profiles of the adhesion specimens for each group under electron microscopy $(5,000 x)$. It can be seen that when the bonding interface was magnified up to 5,000 times, micro cracks became visible on the surface of the NT-C and NT-U groups without coating primers (Figure $3 A, 3 B$ ). The cracks were incompletely continuous. Microcracks were also observed on the surface of MS-U group, but its cracks were narrower and shorter than those of the NT group. The resin adhesives were closely combined with the zirconic ceramics without obvious microcracks for other groups. The observations from microscopy confirmed that the influences exerted by the Clearfil SA Cement and the RelyX Unicem on the porcelain and the adhesives have no significant difference.

\section{Discussion}

The surface treatment agent has a wetting effect on the surface of the ceramic layer, which is conducive to the flow and penetration of the adhesive, forming a micro interlocking effect and generating mechanical bonding force; The functional monomer in the surface treatment agent can form a chemical covalent bond between the adhesive and zirconia to form a chemical binding force; The hydroxyl (-OH) in the functional monomer of the surface treatment agent can form a hydrogen bond binding force with the hydroxyl $(-\mathrm{OH})$ on the surface of the ceramic block. The results show that the coating primers of ZPP, RCP, CCP, and MS can increase the bonding strength between the resin adhesives and the zirconia ceramics, with the CCP group demonstrating the most significant effect.

\section{Effect of primer on bonding strength}

According to the energy spectrum analysis of the porcelain surface for each group, the two elements, $\mathrm{N}$ and $\mathrm{P}$ were present on the surface of the ZPP and MS groups. Based on the composition ratio of the coating primers provided by the manufacturers, the $\mathrm{N}$ and $\mathrm{P}$ elements of the ZPP and MS groups probably originated from the MDP molecules and the adhesive monomers with the phosphate groups of the phosphorylated methyl acrylate, respectively. The 
A
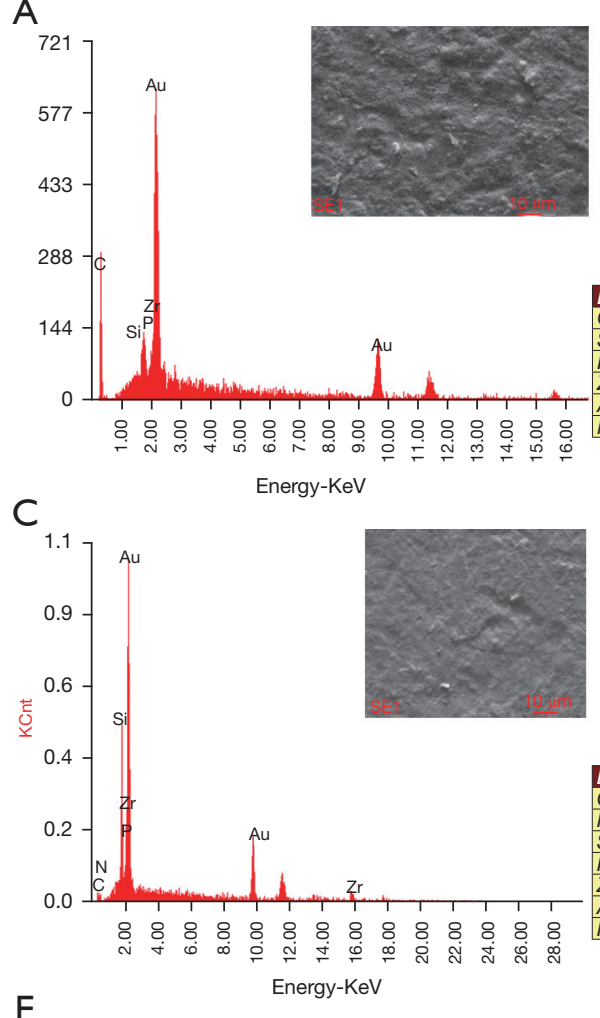

$\mathrm{E}$

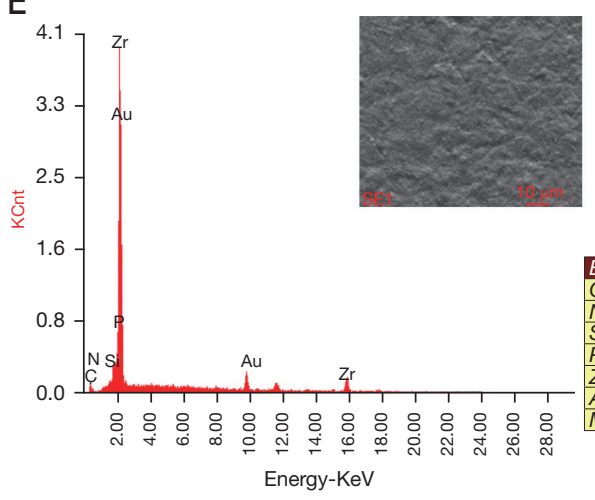

B
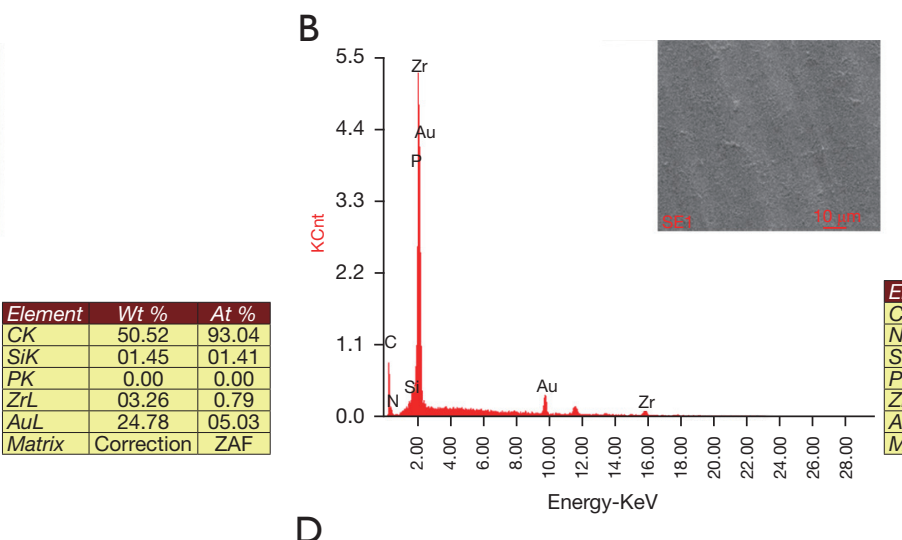

D
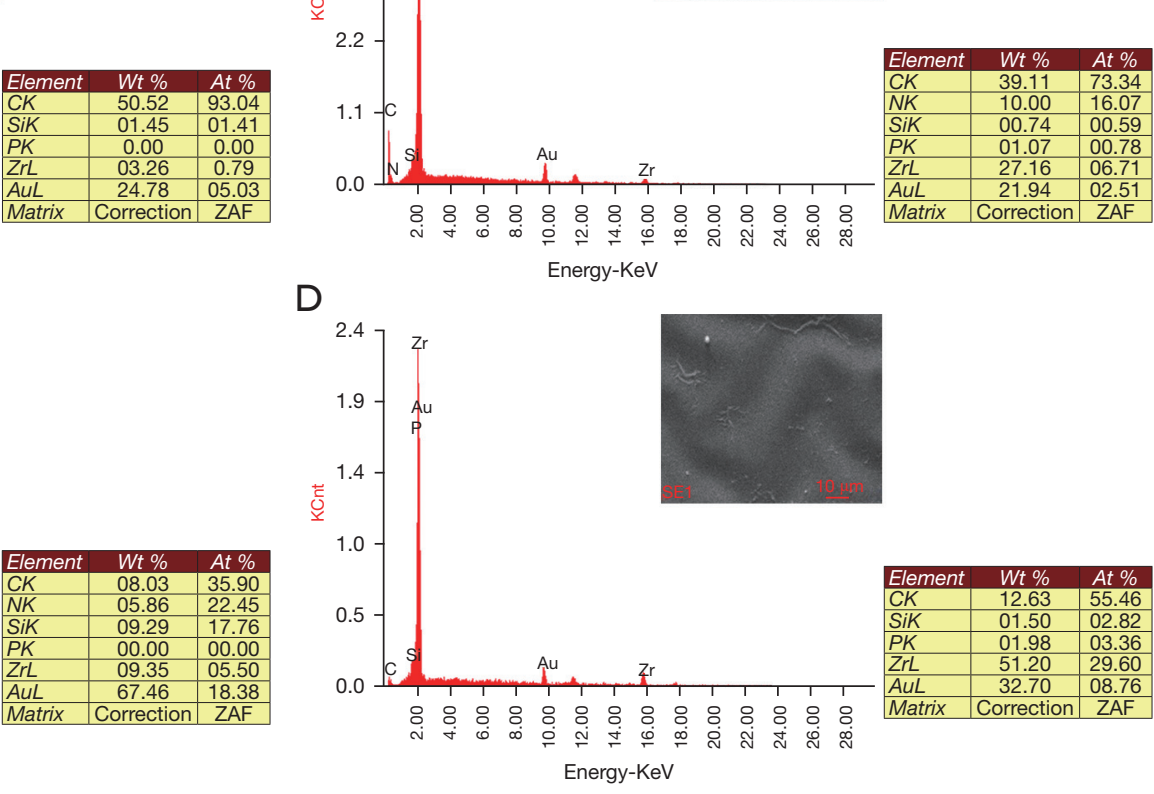

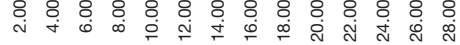

Energy-KeV

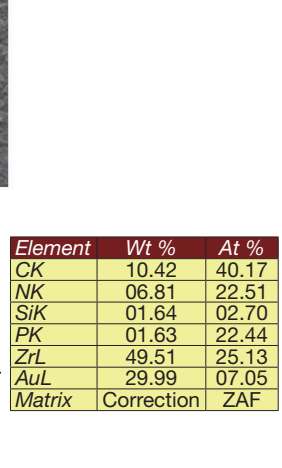

Figure 2 Analysis of surface energy spectrum of porcelain plates after treatment with primer: (A) NT group, (B) ZPP group, (C) RCP group, (D) CCP group, and (E) MS group. The RCP and CCP groups show the highest quality percentage of Si and P elements, respectively.

RCP group contained highest quality percentage of Si element without the $\mathrm{P}$ element, which can be attributed to the major monomer component 3-MPS of the RCP containing silane structures. The mass percentage of the $\mathrm{P}$ elements in the CCP group was the highest, because of the major adhesive monomers of the MDP molecules with the phosphate groups. The CCP and the ZPP groups consist of the coating primers with MDP as their major functional component. Combined with the shear strength data analysis (the shear strength of the ZPP group was smaller than that of the CCP group), it can be speculated that the residual concentration of MDP on the surface of CCP group may be higher than that of the ZPP group.

In regards to the surface microscopic morphology and bonding interface between the zirconic porcelain and coating primers, microcracks could be observed in the groups without coating primers, while the surface roughness was decreased for most groups treated by the coating 

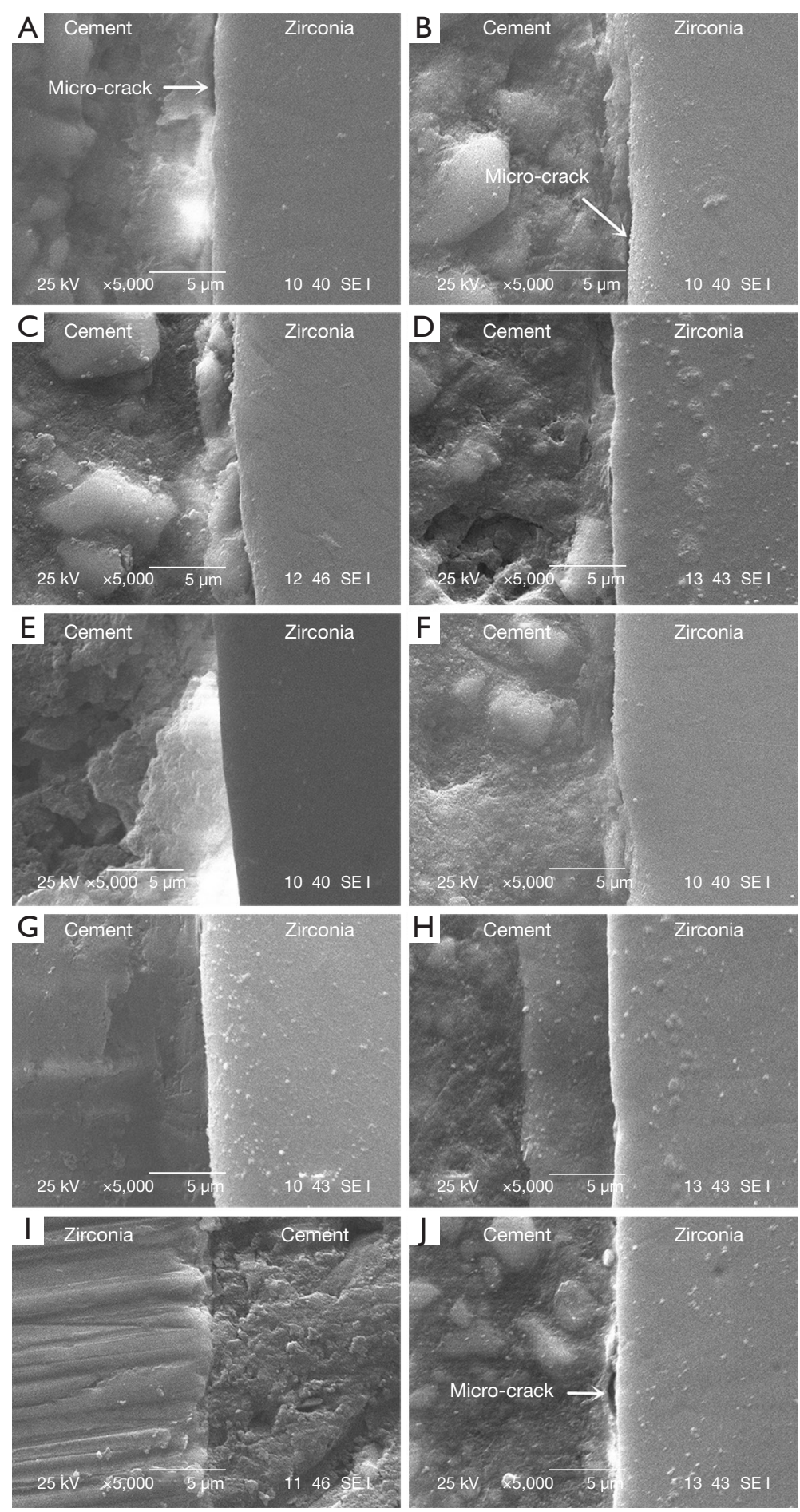

Figure 3 Bonding interface profiles of the adhesion specimens for each group under electron microscopy (5,000×). (A) NT-C, (B) NT-U, (C) ZPP-C, (D) ZPP-U, (E) RCP-C, (F) RCP-U, (G) CCP-C, (H) CCP-U, (I) MS-C, and (J) MS-U. The arrows in panel A, B, and J indicate the microcracks in the NT-C, NT-U, and MS-U groups respectively. In the other groups, resin adhesives were closely combined with zirconic porcelain without obvious microcracks. 
primers, indicating that a tight bond was made between resin adhesives and the zirconic porcelain. This illustrates that the coating primers penetrated into the concave and convex structures of the porcelain surface with tight adhesion, reacting with the hydroxyl on the surface of the porcelain and the active monomers of adhesives. Moreover, these coating primers can produce a strong chemical bond with the resins, which compensate for the excessive viscosity of the resin adhesives which make them unable to completely infiltrate into the microscopic structures of the surface porcelain.

As regards the bonding fracture modes and the bonding force before and after the cold-hot circulation, the bonding strength between the zirconia and resin adhesives was improved by the four kinds of coating primers used in this experiment. However, after artificial aging, only the CCP group showed mixed failure after the cold-hot circulation. Compared to the CCP group, the ZPP, RCP, and MS groups exhibited slight advantages, which is consistent with the research results by May et al. (21). This might be explained by the acid-based polymerization from the selfadhesive resin cement performance, which is composed of a large number of hydrophilic functional groups, which are easy to be destroyed by hydrolysis (22). This probably caused hydrolysis damage after 2,500 cold-hot cycles, suggesting that the three coating primers exhibited weak hydrolysis stability. In comparison, the CCP group was significantly higher than that of the contrast group, whether before or after cold-hot circulation. This illustrates that the CCP coating primer is resistant to hydrolysis, which can improve not only the adhesion of the zirconic porcelain, but also the durability of the zirconic porcelain and resin bond.

The CCP and the ZPP coating primers used in this experiment contain MDP. CCP is a type of two-component ceramic coating primer, which is dissolved with 3-MPS and 10-MDP into alcohol. Not only can MDP react with porcelain and the resins, but it can also can create an acid environment and promote the rapid coagulation of 3-MPS, improving surface wettability and preventing water adsorption (23). ZPP contains MDP and carboxylic acid monomers which are produced by dissolving the hydrophilic components [MDP, carboxylic acid monomer and methylacrylic monomer (HEMA)] and the hydrophobic resin monomer (Bis-GMA) components into ethanol and water at the same time. The carboxylic monomers are a kind of acid adhesive monomer which can facilitate the reaction between MDP and porcelain (24).

\section{Analysis of action mechanism of four primers}

When each of CCP and ZPP is combined with MDP adhesives, the shear strength of the CCP + Clearfil SA Cement group is significantly higher than the ZPP + Clearfil SA Cement group. This can be ascribed to the fact that CCP and Clearfil SA Cement derive from the same manufacturer and are compatible, resulting in a more powerful chemical reaction for CCP. Furthermore, Wang et al. confirmed that when the drying pressure is $0.3 \mathrm{MPa}$, applying a layer of CCP coating primer can obtain the maximum shear strength (25). In Wang et al. study, when the drying pressure was too low, the shear strength was relatively low, and the groups with the higher pressure could not withstand the cold-hot circulation (25). However, when the air gun pressure was $0.2 \mathrm{MPa}$, the shear strength of ZPP was the highest; the higher the pressure was, the lower the strength was Papacchini et al. have also asserted that the dry pressure applied on the coating primers could exert significant influences on the bonding strength (26). Therefore, the pressure of the air gun may be responsible for the lower adhesion of the ZPP group compared to that of the CCP group, where it may be the residual solvents on the surface and the influence of the coating primers on the surface topography of the zirconia $(27,28)$.

CCP group demonstrated the highest shear strength before and after the cold-hot circulation, because the coating primers were fully wetting the surface of zirconic porcelain, and the adhesion monomer content of the coating layer had the sufficient crosslinking reaction with the porcelain, which greatly increased the chemical retention force. The reason that shear strength weakens after cold-hot circulation is that the application of coating primers reduces the roughness of the porcelain surface, and makes the mechanical retention function drop, so that the resins are unable to fully penetrate into the small dents on the surface of the porcelain. This may also lead to hydrolysis breakage in some crosslinking structures ( $\mathrm{Zr}-\mathrm{O}-\mathrm{P})$. Additionally, there are residual solvents on the layer of the coating primers with a relatively low concentration of MDP, which results in an inadequate chemical action. Hence, three conditions are needed to obtain an optimal performance in coating primers: the moderate coating thickness, complete coverage of the zirconia surface, and a substantial presence of the coating primers on the surface of the porcelain.

Without the silane component, ZPP exhibits low viscosity, and can easily dry to a thin film under the same the pressure of the air gun (27). When the residual solvents are 
removed, the airflow can induce the loss of partial adhesive monomers (MDP). After the cold-hot circulation, the bonding strength of ZPP group also declines. The HEMA in the ZPP is a kind of hydrophilic solvent, which is hard to volatize. When HEMA is not optimally cleaned or is leaving too many residuals, the hydrolysis of the bonding interface can easily occur, which destroys the crosslinking structures between the porcelain and the resins $(28,29)$.

RCP is a kind of modified silane coupling agent, which contains silane molecules and adhesive active ingredients, including 3-MPS (30). These monomers can reduce the surface tension of the adhesives, and improve the wettability on the surface of the porcelain, which is consistent with the previously performed analysis of the surface energy spectrum (Figure 2). In our study, Si element on the surface of the RCP group was the highest. After sandblasting the formation of a rough surface on the porcelain, the application of the coating primers infiltrate into each dent of the porcelain, and simultaneously react with the monomer components in the resins. The composition of RCP mainly consists of silane, meaning that the chemical interaction with the porcelain surface is not as strong as that of the CCP, which is consistent with our experimental results.

MS contains $4 \mathrm{Wt} \%$ adhesive monomers and $96 \mathrm{Wt} \%$ ethanol solvents, and can be used for all types of fixed prostheses. A single bottle of MS contains a variety of coupling agents, including silane molecules, phosphorylated methacrylate, etc.

For the RCP and MS, if the silane molecules freely exist on the surface of porcelain without timely condensation, the silane molecules can easy be destroyed by hydrolysis. Under great pressure, the free silane molecules on the surface can be removed, the low polysiloxane of the innermost layer of the bonding interface can then resist hydrolysis (31). Under mild pressure, the coating primer film on the ceramic surface after sandblasting is thicker, making the porcelain surface smooth and reducing the surface roughness with the micromechanical fixation of resin adhesives. When the surface morphology treated by MS and the RCP is observed under our electron microscopy, the coating primers appear thinner, and the irregular surface of the porcelain after sandblasting is clearly visible. Therefore, residual solvents cannot be a result of over primer-coating.

However, the chemical bonds generated between the RCP and MS porcelain reaction are not as stable as the chemical action between MDP, zirconic porcelain, and resins. Therefore, similar to CCP and ZPP, hydrolysis also occurs after the cold-hot circulation (31), which explains the reason for the decrease in bonding strength of the MS and RCP groups after the cold-hot circulation in this experiment.

\section{Effect of two cement on bonding strength}

The influences of two kinds of coating primers (the Clearfil SA Cement and the RelyX Unicem Cement) on the adhesion between the zirconic porcelain and the resins are similar. With both adhesives, shear strength decreased significantly after the cold-hot circulation in this experiment, which is in agreement with the results of Stawarczyk (31). Clearfil SA Cement contains MDP, the Bis-GMA, DMA, and other elements, whose main functions are to combine with the methyl methacrylate in the resins to gain a higher adhesive strength and stability (24). This makes it easier to penetrate into the dents on the porcelain surface after sandblasting, and improves the mechanical strength and the solvent resistance of the adhesives (18).

Unlike Clearfil SA, RelyX Unicem is based on methyl methacrylate. It has an improved composition compared to traditional resin adhesives, and has a novel filling and initiator system with $30-40 \mathrm{wt} \%$ of methyl methacrylate monomers modified by phosphate and nearly $70 \mathrm{wt} \%$ of inorganic fillers. These monomers can rapidly polymerize to form highly cross-linked structures under photocuring, so that the adhesives obtain high mechanical strength and structural stability. Also, the phosphate groups of the methyl methacrylate monomers can react with the hydroxyl groups on the zirconic porcelain surface over the tooth surface. The acid composition of the phosphate groups can make the polluted layers of porcelain and the tooth surface dissolve, facilitating the adhesives to penetrate into the dents on the surface of the zirconic porcelain, thus enhancing the mechanical retention force.

Previously, some researchers reported that the combined use of the resin adhesives with MDP could enhance the durability of bonding strength, and its effect was significantly better than that of other adhesives. The two kinds of adhesives used in this work demonstrated no significant difference (5). Under electron microscopy, the roughness of all the porcelain surface after primer coating decreased, and the porcelain surface treated by the ZPP and the CPP were especially smooth. When coated by thin films, the Clearfil SA Cement and the resin adhesives are able to completely penetrate into the irregular dents on the porcelain surface after sandblasting, leading to 
a decrease of the reaction area for the MDP molecules. When the effective area decreases, the relative content of MDP molecules on the bonding interface is relatively low. Furthermore, the structure of the Clearfil SA is composed of the A and B pastes, which need to be manually mixed in the operation. The ratio cannot be accurately controlled, suggesting that the adhesives have high technical sensitivity in their operation process, which explains the inferiority for the adhesives with MDP in the bonding strength compared with other adhesives.

Although the bonding effects of the Clearfil SA and the RelyX Unicem cement were similar in our experiment, shear breakage increased after the cold-hot circulation in all the experimental groups that used RelyX Unicem. This can be explained by the fact that RelyX Unicem has higher viscosity and weaker wettability than Clearfil SA with MDP, and its inherent hydrolysis is stronger than the strength formed by the chemical bonds of the methyl methacrylate phosphate $(32,33)$.

\section{Conclusions}

The four coating primers tested in our study, Z-Prime Plus, Rely X Ceramic Primer, Clearfil Ceramic Primer, and Monobond-S, were found to effectively improve the bonding strength of the zirconia, while the performance of the Clearfil Ceramic Primer was significantly superior. Clinically, these primers can be considered the preferred surface treatment materials for zirconic porcelain restoration. Cold-hot circulation can reduce the bonding strength between zirconia porcelain and resins, and the use of the Clearfil Ceramic Primer can enhance the durability of the bonding strength. Furthermore, Clearfil SA cement and RelyX Unicem cement have similar adhesive effects on zirconia.

\section{Acknowledgments}

Funding: This work was supported by Natural Science Foundation of Hunan Province, China (2021JJ40965, 2012FJ3124 and 09JJ3029).

\section{Footnote}

Data Sharing Statement: Available at https://atm.amegroups. com/article/view/10.21037/atm-21-4909/dss

Conflicts of Interest: All authors have completed the
ICMJE uniform disclosure form (available at https://atm. amegroups.com/article/view/10.21037/atm-21-4909/coif). The authors have no conflicts of interest to declare.

Ethical Statement: The authors are accountable for all aspects of the work in ensuring that questions related to the accuracy or integrity of any part of the work are appropriately investigated and resolved.

Open Access Statement: This is an Open Access article distributed in accordance with the Creative Commons Attribution-NonCommercial-NoDerivs 4.0 International License (CC BY-NC-ND 4.0), which permits the noncommercial replication and distribution of the article with the strict proviso that no changes or edits are made and the original work is properly cited (including links to both the formal publication through the relevant DOI and the license). See: https://creativecommons.org/licenses/by-nc-nd/4.0/.

\section{References}

1. Tinschert J, Zwez D, Marx R, et al. Structural reliability of alumina-, feldspar-, leucite-, mica- and zirconia-based ceramics. J Dent 2000;28:529-35.

2. Qeblawi DM, Muñoz CA, Brewer JD, et al. The effect of zirconia surface treatment on flexural strength and shear bond strength to a resin cement. J Prosthet Dent 2010;103:210-20.

3. Kern M. Bonding to oxide ceramics-laboratory testing versus clinical outcome. Dent Mater 2015;31:8-14.

4. Luthardt RG, Holzhüter M, Sandkuhl O, et al. Reliability and properties of ground Y-TZP-zirconia ceramics. J Dent Res 2002;81:487-91.

5. Aboushelib MN, Kleverlaan CJ, Feilzer AJ. Effect of zirconia type on its bond strength with different veneer ceramics. J Prosthodont 2008;17:401-8.

6. Yamaguchi H, Ino S, Hamano N, et al. Examination of bond strength and mechanical properties of Y-TZP zirconia ceramics with different surface modifications. Dent Mater J 2012;31:472-80.

7. Chintapalli RK, Mestra Rodriguez A, Garcia Marro F, et al. Effect of sandblasting and residual stress on strength of zirconia for restorative dentistry applications. J Mech Behav Biomed Mater 2014;29:126-37.

8. Rocca JP, Fornaini C, Brulat-Bouchard N, et al. CO2 and Nd:YAP laser interaction with lithium disilicate and Zirconia dental ceramics: A preliminary study. Opt Laser Technol 2014;57:216-23. 
9. Bottino MA, Valandro LF, Scotti R, Buso L. Effect of surface treatments on the resin bond to zirconium-based ceramic. Int J Prosthodont 2005;18:60-5.

10. Liu ZH, Zhang ZT, Gao WM, et al. Effect of surface conditioning methods on the bond strength of luting cements to zirconia. Beijing J Stom 2012;20:61-3.

11. Amaral M, Belli R, Cesar PF, et al. The potential of novel primers and universal adhesives to bond to zirconia. J Dent 2014;42:90-8.

12. Liu D, Pow EHN, Tsoi JK, et al. Evaluation of four surface coating treatments for resin to zirconia bonding. J Mech Behav Biomed Mater 2014;32:300-9.

13. Zhong T, Hu DY, Jiang Y, et al. The influence of surface treatment on the shear bond strength between zirconia and self-adhesive resin cement. J Pract Stomatol 2013;29:31-5.

14. Oliveira-Ogliari A, Vasconcelos CS, Bruschi RC, et al. Thermal silicatization: A new approach for bonding to zirconia ceramics. Int J Adhes Adhes 2014;48:164-7.

15. Lüthy H, Loeffel O, Hammerle CH. Effect of thermocycling on bond strength of luting cements to zirconia ceramic. Dent Mater 2006;22:195-200.

16. Wegner SM, Gerdes W, Kern M. Effect of different artificial aging conditions on ceramic-composite bond strength. Int J Prosthodont 2002;15:267-72.

17. Wong JD, Kei Lung CY, Tsoi JK, et al. Effects of a zirconate coupling agent incorporated into an experimental resin composite on its compressive strength and bonding to zirconia. J Mech Behav Biomed Mater 2014;29:171-6.

18. Inokoshi M, Kameyama A, De Munck J, et al. Durable bonding to mechanically and/or chemically pre-treated dental zirconia. J Dent 2013;41:170-9.

19. Ozcan M, Nijhuis H, Valandro LF. Effect of various surface conditioning methods on the adhesion of dual-cure resin cement with MDP functional monomer to zirconia after thermal aging. Dent Mater J 2008;27:99-104.

20. Wu JZ, Xie HF. Effects of primers on short-time bond strength of zirconia ceramics. Stomatology 2012;11:674-6.

21. May LG, Passos SP, Capelli DB, et al. Effect of silica coating combined to a MDP-based primer on the resin bond to Y-TZP ceramic. J Biomed Mater Res B Appl Biomater 2010;95:69-74.

22. Guo L, Zhang JT, Chen CF, et al. Influence of various

Cite this article as: Cao Y, Zhang JF, Ou X, Zhang B, Chen L, Deng XH. The effects of four primers and two cement types on the bonding strength of zirconia. Ann Transl Med 2022;10(5):248. doi: 10.21037/atm-21-4909 luting agents and cyclic loading on microleakage of cast crowns. Inter J Stomatol 2010;37:651-5.

23. Yoshida K, Tsuo Y, Atsuta M. Bonding of dual-cured resin cement to zirconia ceramic using phosphate acid ester monomer and zirconate coupler. J Biomed Mater Res B Appl Biomater 2006;77:28-33.

24. Piascik JR, Swift EJ, Braswell K, et al. Surface fluorination of zirconia: adhesive bond strength comparison to commercial primers. Dent Mater. 2012;28:604-8.

25. Wang C, Niu LN, Wang YJ, et al. Bonding of resin cement to zirconia with high pressure primer coating. PLoS One 2014;9:e101174.

26. Papacchini F, Monticelli F, Hasa I, et al. Effect of airdrying temperature on the effectiveness of silane primers and coupling blends in the repair of a microhybrid resin composite. J Adhes Dent 2007;9:391-7.

27. Perdigao J, Fernandes S D, Pinto A M, et al. Effect of artificial aging and surface treatment on bond strengths to dental zirconia. Oper Dent 2013;38:168-76.

28. Ikeda T, De Munck J, Shirai K, et al. Effect of air-drying and solvent evaporation on the strength of HEMArich versus HEMA-free one-step adhesives. Dent Mater 2008;24:1316-23.

29. Hiraishi N, Breschi L, Prati C, et al. Technique sensitivity associated with air-drying of HEMA-free, single-bottle, one-step self-etch adhesives. Dent Mater 2007;23:498-505.

30. Behr M, Proff P, Kolbeck C, et al. The bond strength of the resin-to-zirconia interface using different bonding concepts. J Mech Behav Biomed Mater 2011;4:2-8.

31. Stawarczyk B, Stich N, Eichberger M, et al. Longterm tensile bond strength of differently cemented nanocomposite CAD/CAM crowns on dentin abutment. Dent Mater 2014;30:334-42.

32. da Silva EM, Miragaya L, Sabrosa CE, et al. Stability of the bond between two resin cements and an yttriastabilized zirconia ceramic after six months of aging in water. J Prosthet Dent 2014;112:568-75.

33. Mirmohammadi H, Aboushelib MN, Salameh Z, et al. Innovations in bonding to zirconia based ceramics: Part III. Phosphate monomer resin cements. Dent Mater 2010;26:786-92. 